\title{
Consideraciones para una teoría general del contrato de secuestro
}

\author{
Fernando Javier Macías Arditto
}

\section{Introducción}

El contrato de secuestro es una figura contractual que pocos códigos civiles regulan, por lo que tiene un tratamiento precario y casi siempre dentro del contrato de depósito. ${ }^{1}$

También posee gran afinidad con el proceso cautelar según la modalidad de secuestro conservativo, ya que el contrato de secuestro presenta una finalidad cautelar (Messineo 1979: 292). Esto ha generado una visión procesal del secuestro.

El contrato de secuestro no es una categoría contractual nueva en nuestra legislación civil. En efecto, aparece con el primer Código Civil, el de 1852, regulado dentro del contrato de depósito, para luego desaparecer durante la vigencia del Código Civil de 1936. Aparece nuevamente con el Código Civil de 1984, pero como figura contractual típica (Arias-Schreiber 1995: 228). Su permanencia es discutida en la legislación civil, debido a la confusión existente en torno a esta figura contractual, y a que se le aprecia, fundamentalmente, como una modalidad especial e independiente del

1 Por ejemplo, el Código Civil español. 
contrato de depósito, la figura general. Entre los juristas nacionales, Arias-Schreiber (1995: 229) defiende las bondades del contrato de secuestro: "Creemos, empero, que debe mantenerse, pues no irroga perjuicio alguno". Tanto en el ámbito internacional como nacional, el contrato de secuestro no tiene un tratamiento doctrinal y normativo exhaustivo que haga posible un análisis completo sobre la materia y permita avizorar nuevos horizontes en el futuro.

\section{Antecedente legislativo nacional}

En el libro tercero, sección cuarta, "De los contratos reales", el Código Civil de 1852 dedicaba 39 artículos al contrato de depósito: del artículo 1845 al 1884. Desde el artículo 1880 hasta el artículo 1882, este código regulaba lo que denominaba "El depósito de cosas litigiosas". Las características más importantes del contrato de secuestro en este cuerpo legal eran las siguientes:

a. Regulación precaria del contrato de secuestro.

b. Se le normó dentro del contrato de depósito; por tanto, le eran aplicables sus demás disposiciones de manera complementaria.

c. No se usaba nomenclatura especial para designar al contrato de secuestro, sino la terminología propia del contrato de depósito, ya que se le consideraba una especie de este.

d. Regulación de dos modalidades: el depósito de cosa litigiosa hecho por consentimiento (artículo 1881) y el depósito judicial (artículo 1882); y cuándo terminaban ambas formas.

Este antecedente legislativo marcó la pauta del contrato de secuestro en nuestro derecho civil. Sin duda, las taras que aún padece la institución - no solo en nuestra codificación civil, sino también en casi todo el mundo y en la doctrina - son producidas por la asimilación normativa del secuestro convencional al depósito como una de sus modalidades.

\section{Terminología empleada}

El Diccionario de la lengua española registra secuestrar (Real Academia Española: definición de secuestrar), cuyas acepciones son: 
a. Depositar judicial o gubernativamente una alhaja en poder de un tercero hasta que se decida a quién pertenece.

b. Embargar judicialmente.

c. Retener indebidamente a una persona para exigir dinero por su rescate, o para otros fines.

d. Tomar por las armas el mando de un vehículo (avión, barco, etc.), reteniendo a la tripulación y pasaje, a fin de exigir como rescate una suma de dinero o la concesión de ciertas reivindicaciones.

Por su parte, secuestro (Real Academia Española: definición de secuestro) significa:

a. Acción y efecto de secuestrar.

b. Bienes secuestrados.

c. Juez, árbitro o mediador.

d. Porción de hueso mortificada que subsiste en el cuerpo separada de la parte viva.

e. Depósito judicial por embargo de bienes, o como medida de aseguramiento en cuanto a los litigiosos.

Como se aprecia, las acepciones son numerosas, e incluso de naturaleza disímil. En efecto, el derecho civil usa la acepción contractual; el derecho penal, la de contenido delictual - acepciones 3 y 4 del verbo secuestrar-; y el procesal civil utiliza la acepción procesal, de medida cautelar o de embargo - acepciones 1 y 2 del verbo y 2 y 5 del sustantivo-. Así, hablamos de secuestro convencional cuando nos referimos al contrato de secuestro, y de secuestro judicial cuando señalamos el proceso o medidas cautelares de evidente naturaleza judicial.

Conviene observar la terminología debido a que resulta común encontrar en doctrina denominaciones como secuestro convencional - usada por lo general para diferenciarlo del secuestro judicial, desde una óptica procesal- y contrato de secuestro - para identificar a esta figura contractual-.$^{2}$

2 Nuestro Código Civil usa esta última denominación. 
Creemos que de la terminología adoptada depende la visión y regulación que se le da al tema. Al ser, desde nuestra perspectiva, el secuestro de naturaleza contractual, la denominación debe resaltar esa naturaleza jurídica por sobre cualquier otra.

No existe en derecho una institución o categoría jurídica genérica denominada secuestro. Este término polisémico debe unirse a otras palabras para tener significado jurídico y existencia fenomenológica como institución y categoría jurídica. De ahí surgen las diversas instituciones jurídicas que contienen el vocablo secuestro: contrato de secuestro o secuestro convencional, delito de secuestro y secuestro conservativo o secuestro judicial. Esta variada terminología olvidó darle un tratamiento exhaustivo al secuestro. ${ }^{3}$ Para efectos de nuestro trabajo, consideramos que la nomenclatura correcta es la de contrato de secuestro, usada por nuestro Código Civil. Esta no solo expone su fuerte naturaleza contractual, sino que se aparta de las otras nomenclaturas, como la de secuestro convencional, pues alude a una especie de secuestro de dos existentes, siendo la otra especie el secuestro judicial. ${ }^{4}$

Esta última nomenclatura le da al secuestro una visión procesal que, a nuestro juicio, no es correcta. En efecto, la visión procesal del secuestro es causada por la confusión (terminológica y de identidad) que ronda esta forma contractual desde sus orígenes. Secuestrar significa, en términos generales, "raptar", "capturar una cosa o persona de manera violenta". De ahí los siguientes contactos del secuestro con el mundo jurídico: con el derecho penal, cuando se produce el secuestro o rapto de personas; con el derecho procesal, cuando se solicita al juez el secuestro conservativo de los bienes del demandado; y con el derecho civil, cuando de manera voluntaria se accede a secuestrar los bienes litigiosos a efectos de que un tercero los custodie.

3 Por ejemplo, el Código Civil venezolano trata en el libro tercero, título XV, capítulo II, Del secuestro, sección I, De las diversas especies de secuestro.

4 Aunque la doctrina trate al secuestro convencional y judicial como especies, es importante resaltar que el problema no es producido por el contenido de ambas, sino por una inadecuada terminología. Messineo sostiene que "el secuestro convencional tiene estrecho parentesco, en cuanto a la función, con el secuestro judicial (art. 670, del Cód. Proc. Civ.), aunque se distinga de él por su carácter de instituto de derecho sustancial y por su índole contractual" (1979: 292). 
Entonces, el secuestro es un fenómeno social que ha sido recibido por el derecho desde tres ángulos: civil, procesal y penal; por tanto, no existe una figura jurídica general de secuestro, sino simplemente las tres categorías anotadas, con sus características propias que las diferencian entre sí. Una misma palabra las une, pero eso no debe llevarnos necesariamente a la rápida conclusión de que son especies jurídicas derivadas de una institución común.

\section{Concepto de contrato de secuestro}

El derecho romano (Petit 1980: 477) entendía por secuestrum "el depósito en manos de un tercero, sequester, de una cosa sobre la que hay contienda entre dos o varias personas, con cargo de conservarla y devolverla a la parte que gane la causa". En los niveles doctrinal y normativo, esta definición no ha sufrido mayores cambios. En efecto, nuestro Código Civil lo define en el artículo 1857 de manera similar: "Por el contrato de secuestro, dos o más depositantes confían al depositario la custodia y conservación de un bien respecto del cual ha surgido controversia".

La doctrina internacional acentúa el rasgo característico del contrato de secuestro: la conservación y custodia de un bien sobre el que recae una controversia. Así, Colin y Capitant (1949: 702) $)^{5}$ lo definen como "el depósito hecho, en manos de un tercero, de una cosa sobre la cual dos personas tienen o pretenden tener, respectivamente, algún derecho, y llevado a cabo mientras se sustancian definitivamente los aludidos derechos". Por su parte, Messineo dice del secuestro que "es el contrato por el cual, a una de las partes denominada secuestratario, se le confía, por otro sujeto (secuestrante), una cosa respecto de la cual haya surgido una controversia; ello tiene por objeto hacer posible la custodia y posterior restitución de la cosa a quien corresponda una vez definida la controversia" (1979: 292).

Díez-Picazo y Gullón sostienen que es "[...] la medida cautelar acordada por las partes, que tiene como especialidad que la restitución ha de hacerse a una sola de ellas que inicialmente está todavía indeterminada.

5 Nótese que usan la denominación de secuestrante y secuestratario para aludir a los sujetos del contrato de secuestro. 
En nuestro derecho positivo tal figura es un genuino depósito voluntario" (1990: 474). Estos autores enfatizan la finalidad del secuestro y no la obligación de conservación y custodia. Sin embargo, para lograr la finalidad cautelar del secuestro debe cumplirse a cabalidad con la obligación de custodia y conservación a cargo del secuestratario. En términos muy similares, varios códigos civiles definen el secuestro; así, tenemos el Código Civil italiano (artículo 1798), el boliviano (artículo 869), el colombiano (artículo 2276), el mexicano (artículo 2539) y el uruguayo (artículo 2285), que resaltan la dual modalidad convencional y judicial del secuestro.

De las definiciones anotadas, podemos identificar elementos comunes que tipifican plenamente esta forma de contratación. Primero: es un contrato; segundo: el objeto es una cosa litigiosa; tercero: la indeterminación de la titularidad de la cosa o del mejor derecho a poseerla (la controversia); cuarto, y por último: la restitución a quien resulte ser el titular de algún derecho sobre la cosa (pluralidad de sujetos activos).

Nosotros definimos el contrato de secuestro como "el contrato por el cual dos o más personas, llamadas secuestrantes, entregan en posesión una cosa litigiosa o controvertida a un tercero, denominado secuestratario, para que la custodie y conserve hasta que se adjudique el derecho discutido a uno de los secuestrantes".

\section{Características del contrato de secuestro}

El secuestro es un contrato de naturaleza temporal, pues se entrega la posesión del bien al depositario para que luego lo devuelva eliminada la controversia. En el contrato de secuestro, el secuestratario debe devolver la cosa a quien es declarado vencedor de la controversia, de conformidad con el artículo 1866 del Código Civil. ${ }^{6}$

El secuestro es un contrato de duración indeterminada, pues se ejecuta hasta que la controversia sea zanjada y se entregue el bien a quien le corresponda. Es decir, es un contrato en donde el plazo de vencimiento no se encuentra determinado en el momento de la celebración del contrato, cualificado por el procedimiento - judicial o extrajudicialque los depositantes adopten para solucionar la controversia.

6 Artículo 1866.- El bien debe ser entregado, conforme al resultado de la controversia, a quien le corresponda. 
Es de tracto sucesivo o de ejecución continuada, en tanto que, entregado el bien al depositario, la posesión del bien es ininterrumpida hasta el momento en que deba verificarse la restitución de la cosa a quien resulte vencedor de la controversia, depositario que durante dicho lapso debe observar las obligaciones que voluntariamente ha asumido: conservación y custodia, sobre todo. Tratándose de una obligación de hacer y en particular de una obligación de conservar y custodiar una cosa, la ejecución de dicha prestación se efectúa durante el transcurrir del plazo del contrato, siendo ambos fenómenos (tiempo y obligación de hacer) simultáneos y paralelos.

Es un contrato generalmente oneroso, ya que el depositario recibe a cambio una contraprestación por los servicios de conservación y custodia que presta. Si bien la definición del contrato de secuestro en nuestro Código Civil no menciona nada al respecto - lo cual puede generar problemas de interpretación-, la doctrina es mayoritaria al considerar al secuestro como un contrato generalmente oneroso, rasgo que lo diferencia del depósito voluntario, que es gratuito. Sin embargo, coincidimos con un sector de la doctrina que considera, excepcionalmente, que el contrato de secuestro pueda ser gratuito (Arias-Schreiber 1995: 231), ${ }^{7}$ modalidad posible merced al derecho de los contratantes a diseñar internamente su relación contractual en virtud del principio constitucional de libertad contractual.

Como es oneroso, adquiere la calidad de contrato con prestaciones recíprocas, pues el servicio y la retribución pactados son prestaciones que guardan perfecta relación recíproca entre sí, tanto desde su génesis como durante el periodo de ejecución obligacional, existiendo interdependencia prestacional (la razón de una prestación es la existencia de la prestación recíproca). Dentro de esta tendencia se ubica en los códigos boliviano (artículo 870), venezolano (artículo 1782) e italiano (artículo 1802), para quienes es generalmente oneroso, salvo pacto en contrario.

7 Al respecto, Messineo (1979: 294) afirma: “El secuestro es contrato oneroso (salvo que las partes lo hagan gratuito); por tanto, el secuestratario tiene derecho a una compensación, y tiene también derecho al reembolso de los gastos y de cualquiera otra erogación que haya hecho para la conservación y administración de la cosa (art. 1802)". 
Nada menciona el Código sobre el tipo de contraprestación que debe el depositante al depositario por los servicios prestados en el contrato de secuestro. Consideramos que la contraprestación debe ser dineraria. De pactarse otras formas de retribución, estaríamos ante cualquier modalidad contractual atípica de hago para que des, reguladas como prestaciones de servicios. ${ }^{8}$

También es un contrato conmutativo y no aleatorio, en tanto que las partes conocen de antemano los riesgos y sacrificios patrimoniales que les reportará la ejecución del contrato. Además, el secuestro es un contrato principal, ya que no depende de ninguna otra figura contractual previa para su celebración y existencia - como sí ocurre en el caso del subarrendamiento y, en general, en la teoría de los subcontratos-. En la doctrina italiana es considerado como un contrato mixto (Messineo 1979: 293).

Transfiere la posesión, ya que al ser un contrato temporal y no traslativo de dominio, los derechos reales sobre la cosa también tienen dicha característica. La posesión es el derecho real que, en defecto del derecho de propiedad, cede temporalmente ciertos atributos sobre una cosa a un tercero para que luego la devuelva a quien le transfirió el derecho. En nuestro caso, se devolverá la cosa a uno de los secuestrantes cuando la controversia se extinga y se le adjudique el derecho a alguno de ellos. Se transfiere la posesión y no otro derecho real, como el uso, pues el contrato de secuestro es un contrato con obligación de dar, en donde el secuestrante o los secuestrantes entregan físicamente la cosa litigiosa o controvertida a un tercero para que la conserve y custodie por cierto tiempo y luego la devuelva, eliminada la controversia. Como sabemos, las obligaciones de dar constituyen derechos reales. $\mathrm{Y}$ al no ser posible transferir la propiedad de la cosa secuestrada, se transfiere su posesión. Por tanto, el secuestratario no cuenta con la tenencia de la cosa, no es tan solo un nudo poseedor, pues detenta la cosa para sí; la posee no solo físicamente, sino con ánimo de poseerla.

El contrato de secuestro genera una obligación de hacer, pues el secuestratario queda obligado a desempeñar sobre la cosa actos tendientes a

8 Artículo 1757.- Son también modalidades de las prestaciones de servicios, y les son aplicables las disposiciones contenidas en este capítulo, los contratos innominados de doy para que hagas y hago para que des. 
custodiarla y conservarla hasta que sea devuelta una vez resuelta la controversia, lo que constituye la finalidad negocial del contrato de secuestro.

Es un contrato formal, en tanto que para su validez y existencia depende del cumplimiento de la formalidad exigida por ley bajo sanción de nulidad. Es un contrato ad solemnitatem, pues la ley exige la forma escrita, bajo sanción de nulidad. El secuestro no es un contrato real, pues el perfeccionamiento del contrato no se genera con la entrega física dela cosa. Deigualforma, nosolo su nacimientoy perfeccionamiento es consecuencia de la voluntad de los declarantes, sino que, por añadidura, el efecto provocado es de naturaleza obligacional, pues nuestro sistema contractual solo genera obligaciones a cargo de una o de ambas partes.

También podemos decir que el contrato de secuestro es un contrato nominado y típico. Es nominado, pues esta figura contractual tiene un nomen juris que lo identifica e individualiza en el mundo jurídico, no solo otorgado por la doctrina, sino también por la legislación. Es típico, pues al estar incorporado en nuestro ordenamiento civil, esta fuente del derecho le otorga un tratamiento normativo y le da tipicidad como figura contractual en el mundo normativo.

\section{Formalidad del contrato de secuestro}

La formalidad escrita facilita la prueba de la existencia e interpretación del contrato de secuestro, pues el único medio probatorio que deberán aceptar los jueces es la prueba documental donde conste el acuerdo. Además, la formalidad escrita se constituye en una garantía de seguridad para los contratantes, quienes ven reducidos los riesgos de la operación por una certidumbre en cuanto a la existencia del contrato de secuestro. ${ }^{9}$

Nuestro Código no menciona la naturaleza del documento en donde conste el contrato; por lo tanto, puede constar en documento público o

9 “Sería, en efecto, riesgoso y susceptible de generar confusión con otras figuras jurídicas si el secuestro pudiera ser probado por cualesquiera de los medios probatorios que permite la ley, esto es, en función del principio de libertad de forma" (Arias-Schreiber 1995: 235). 
privado. En efecto, no deberá considerarse cumplida la formalidad si las partes no suscriben el documento respectivo. ${ }^{10}$

\section{Secuestro convencional y depósito voluntario}

El secuestro convencional y el depósito voluntario tienen la misma obligación principal: conservación y custodia. Sin embargo, por poseer un elemento en común no se debe llegar a la fácil conclusión de que son o la misma institución o dos especies de un mismo género. Casos similares han existido en el derecho romano, como las locaciones, que durante muchos siglos fueron consideradas obligación de hacer, incluida la locación de cosas - hoy llamada arrendamiento en nuestro Código Civil-, con tratamiento doctrinal y normativo diferente de las demás formas locativas. Contratos con una misma obligación eran, con probabilidad, fácilmente asimilados a una figura contractual típica. Estos esquemas contractuales considerados inmutables no fueron refutados, sino hasta tiempos recientes.

Sin embargo, esto no sucedió necesariamente con los contratos traslativos de propiedad, que, albergando una misma obligación - la de transferir -, no tienen un tratamiento doctrinal y normativo gemelar (como la compraventa, que deriva de la permuta al aparecer el dinero como medio de cambio), sino que diversas especies contractuales, como la venta, el suministro, el mutuo, la donación y la permuta, son consideradas contratos autónomos, principales, vinculados exclusivamente por una misma obligación, pero son contratos independientes. Entonces, afirmamos que ambas figuras contractuales no son iguales, pese al tronco común que las vincula. Más que similitudes, entre ambos contratos existen diferencias que los hacen independientes y autónomos dentro del mundo jurídico.

\section{Sujetos}

En cuanto a los sujetos contratantes, queremos subrayar la ausencia de una nomenclatura propia para denominarlos en el contrato de

10 No se debe confundir la formalidad como un requisito para la validez del contrato de secuestro, con el aspecto meramente probatorio del documento. 
secuestro. Sabido es que las partes contratantes tienen una particular forma de ser denominadas, ${ }^{11}$ pero a quien celebra un contrato de secuestro se le llama depositante o depositario, según corresponda. Esta nomenclatura, adoptada por nuestro Código Civil, confirma nuestras fundadas sospechas de que el tratamiento dogmático y normativo del contrato de secuestro ha sido, desde siempre, abordado poco seriamente.

Además, nuestro Código menciona a "dos o más depositantes" como sujetos activos del secuestro, en clara alusión a una necesaria pluralidad de secuestrantes, quienes son los que deben estar necesariamente vinculados por un conflicto respecto de la cosa objeto de contratación. La vinculación entre los sujetos activos del contrato de secuestro es un hecho particular, pues están vinculados por un litigio o controversia sobre la cosa común, no siendo necesariamente condóminos. Significa que la especial situación de los secuestrantes está adjetivada por la presencia de una circunstancia que los motivaría a celebrar un contrato de secuestro, convirtiéndose esta circunstancia en uno de los elementos distintivos del secuestro convencional.

En cuanto a la persona del secuestratario, no existe limitación legal alguna: puede ser persona natural o jurídica. Desde luego, si es persona natural, debe ser capaz. En cuanto a la capacidad exigida, debe ser de ejercicio. La doctrina nacional no admite la posibilidad de que sea celebrado el contrato de secuestro por incapaces relativos (AriasSchreiber 1995: 230).

Resulta importante reflexionar acerca del rol de la expresión confían del Código, aunque no posea significado en el mundo jurídico. En efecto, la confianza ${ }^{12}$ entre los contratantes es un elemento tipificante de este contrato. La finalidad negocial del contrato de secuestro es la entrega en posesión (para su custodia y conservación) de un bien sobre el que recae una controversia. Entonces, la entrega para su conservación y

11 Por ejemplo, quien adquiere para sí un bien por un precio determinado será el comprador en la compraventa, o quien arrienda su propiedad a un tercero arrendatario será llamado arrendador.

12 "Implicando, como elemento constitutivo, el acto de confiar, o sea una entrega, el secuestro convencional se debe enumerar entre los contratos reales" (Messineo 1979: 292). 
custodia de un bien litigioso a un tercero, se hace en consideración a la confianza que les pueda inspirar a los depositantes la persona del depositario por sus cualidades personales, adquiriendo el contrato el carácter de intuito personae.

\section{Objeto}

El universo de bienes susceptibles de contratación en el secuestro es más amplio que en el depósito. En materia de contrato de secuestro no funciona la regla según la cual "pueden darse en secuestro aquellos bienes que pueden darse en depósito". En el secuestro convencional, la regla aplicable es que "pueden ser secuestrados convencionalmente aquellos bienes susceptibles de ser custodiados y conservados", con lo que el espectro de bienes es más amplio que en el depósito voluntario. De la misma opinión es Arias-Schreiber, para quien puede ser objeto del contrato de secuestro toda clase de bienes, pero susceptibles del deber de custodia. ${ }^{13}$

De manera excepcional, la doctrina francesa sostiene la posibilidad de que el secuestro verse sobre cosas no litigiosas. ${ }^{14}$ Así, los bienes muebles corporales y los inmuebles pueden ser objeto de contrato de secuestro, no solo por no existir prohibición para ello, sino porque cumplen con la regla general arriba anotada.

Nuestro Código Civil no menciona expresamente qué clase de cosas pueden ser objeto del contrato de secuestro. Sin embargo, la legislación comparada sí trata el tema en forma expresa e incluye, de manera unánime, a los inmuebles. Así, tenemos los códigos chileno (artículo 2251),

13 “[... (10) Finalmente, debemos indicar que se extiende a toda clase de bienes, pues el artículo 1857 no hace distingo alguno, pero en la medida en que sean susceptibles, cuando menos, del deber de custodia" (1995: 232).

14 Colin y Capitant, respecto al Código Civil francés, mencionan: “[...] pero el secuestro puede ser también de una cosa no litigiosa, y así sucede, según los términos del art. 602, que los inmuebles sometidos a usufructo deben ser colocados en secuestro cuando el usufructuario no puede encontrar caución" (1949: 702). Sin embargo, es curiosa la mención hecha por los juristas franceses, pues es el único comentario de ese tipo que hemos encontrado en la doctrina. Desde luego, hay que tener presente que una figura contractual típica que podría muy bien llenar dicho espacio es el llamado depósito necesario y no el secuestro, a nuestro juicio. 
venezolano (artículo 1783) y colombiano (artículo 2275, cuya redacción es igual al chileno).

\section{Obligaciones de las partes}

Las obligaciones de los secuestrantes son las siguientes: entregar la cosa, pagar la contraprestación (si la hubiere), pagar los gastos del secuestro y abstenerse de perturbar la actividad del secuestratario tendiente a la conservación y custodia de la cosa. Los secuestrantes están obligados a entregar la cosa al secuestratario, pues esto es una consecuencia contractual en nuestro sistema jurídico. En efecto, los contratos generan obligaciones a cargo de ambas partes, por lo que, una vez celebrado el contrato de secuestro, surge el efecto propio de este: generar la obligación de entregar la cosa.

Pagar la contraprestación y los gastos del secuestro al secuestratario es la segunda obligación de los secuestrantes. En caso de que el secuestro sea oneroso, es lógico suponer que los secuestrantes están en la obligación de retribuir su servicio y reembolsarle los gastos sustentados del secuestro. ${ }^{15}$ La otra obligación de los secuestrantes es una de no hacer, consistente en no perturbar la conservación y custodia del secuestratario. No hemos encontrado en la doctrina ni en la legislación comparada norma semejante. Sin embargo, consideramos de suma importancia dicha obligación, pues estando unidos los secuestrantes por una controversia, la tentación de tener cerca la cosa controvertida, sea para vigilarla o no, puede llevarlos, en un exceso de celo, a perturbar al secuestratario, quien no podría cumplir el encargo a cabalidad.

Recibir la cosa es la primera obligación del secuestratario y recíproca de la obligación de los secuestrantes de entregar la cosa. Así como los secuestrantes están obligados a entregar la cosa, el secuestratario está, a su vez, obligado a recibirla. Sin estas obligaciones cumplidas, el contrato sería imposible de ejecutarse; son obligaciones, pues, de entrada o de apertura contractual.

15 Nuestro Código establece una necesaria solidaridad entre los secuestrantes en el artículo 1863, a fin de que los créditos del secuestratario no se vean burlados fácilmente por algún secuestrante que, no siendo favorecido con la cosa, pretenda olvidarlos. 
Desde otra perspectiva, la recepción de la cosa por parte del secuestratario genera un efecto jurídico inmediato: le hace responsable de la cosa. Los secuestrantes se liberan de responsabilidad sobre la cosa, lo que no significa que transfieren el riesgo propio y típico sobre la cosa, sino que son de cargo del secuestratario la conservación y custodia de esta. El riesgo de la pérdida, deterioro o destrucción de la cosa secuestrada corre a cargo de los secuestrantes, en abstracto, y para el vencedor de la controversia, en concreto. ${ }^{16}$

Con relación a la obligación de conservación y custodia, debemos decir que es el eje de las obligaciones del secuestratario y se ejecuta luego de recibida la cosa; es una obligación de ejecución en el tiempo, pues la ejercerá hasta que deba entregarla al ganador de la controversia. Esta obligación de conservación y custodia tipifica la finalidad del contrato de secuestro: ayuda a que la finalidad cautelar se logre efectivamente. La tercera obligación del secuestratario es administrar la cosa, de acuerdo con el artículo 1859 del Código Civil.

Por último, el secuestratario ha de entregar la cosa secuestrada al vencedor de la controversia; el artículo 1866 de nuestro Código Civil así lo exige. Esta obligación de restitución tiene particularidades que la diferencian de otras obligaciones similares. Por un lado, debe entregarla al vencedor de la controversia y no a quien se la entregó físicamente; por otro lado, debe rendir cuentas de la administración y entregarla con los frutos, si los hubiere.

Del tratamiento legislativo que les dispensa la legislación comparada a las obligaciones de las partes, podemos apreciar que no hay un tratamiento orgánico ni unitario (como sí sucede, por ejemplo, con las obligaciones del arrendador y del arrendatario) de las obligaciones de las partes en materia de contrato de secuestro, siendo la tendencia a asimilarlas a las obligaciones que las partes tienen en materia de depósito voluntario, como es el caso del Código mexicano. Es menester, pues, por la importancia del tema, que estas estén reguladas específicamente dentro del tratamiento legislativo del secuestro convencional, de manera unitaria y cohesionada.

16 El principio res perit domino ("la cosa se pierde para su dueño") afecta a todos los secuestrantes, pues tienen un derecho expectante sobre la cosa, el que se hará cierto una vez eliminada la controversia. 


\section{Obligación de conservación y custodia}

La obligación de conservación y custodia se convierte en el eje principal de las obligaciones del secuestratario. Conservación es la realización de actos que conduzcan a que la cosa mantenga su esencia - características y operatividad en óptimo estado-, de suerte tal que se deben efectuar gastos para lograr dicho cometido. Importa, por consiguiente, mantener a la cosa en condiciones de funcionamiento y buen uso.

Por el contrario, custodiar significa "guardar con cuidado y vigilancia" (Real Academia Española): importa un deber de cuidado, de vigilancia, de protección o guardianía sobre la cosa, de tal modo que el depositario debe evitar exponerla al peligro, debe ponerla a buen recaudo e implementar las medidas necesarias para que el riesgo sobre la cosa sea el mínimo posible, debiendo sustraerla del peligro que pueda importar un detrimento o daño directo sobre ella, en evidente perjuicio del legítimo titular.

La conservación y custodia exigida son los actos de cuidado diligente que realiza el poseedor directo, inmediato, respecto de la cosa poseída, para evitar su destrucción o disminución física. Incluso, autorizada doctrina menciona que el secuestratario debe comportarse como si fuera propietario de la cosa: "[...] debe poner en la guarda de la cosa depositada el mismo celo y cuidado que él pone en la guarda de las cosas que le pertenecen" (Colin y Capitant 1949: 692).

\section{En el contrato de secuestro, la obligación de hacer, según doctrina mayoritaria, es una obligación de medios}

La obligación de hacer, contenida en el contrato de secuestro, es considerada por la teoría de Demogue como una obligación de medios y no de resultados. Es importante que el secuestratario desarrolle el servicio (vale decir, la obligación de conservación y custodia), pues no compromete ningún resultado final, como sí ocurre en el contrato de obra. Consideran el servicio y el fin como dos caras de una misma moneda, de suerte que es imposible que una exista sin la otra. Lo primordial es el énfasis puesto al momento en que el hacer es pactado, para reconocer si una obligación es de medios o de resultado: por un lado, si el énfasis se centra en el servicio propiamente, la obligación será de medios; por el contrario, si el énfasis es el resultado producto del servicio realizado, la obligación será de resultado. 
Por tanto, el pago en la obligación de medios será íntegro si el prestador del servicio realiza el hacer al que se obligó; el pago en las obligaciones de resultado será íntegro si el prestador del servicio entrega al acreedor la obra -opus - prometida. Realmente, el tema va más allá de una mera forma de clasificar las prestaciones en medios y resultados: el verdadero problema se centra, en opinión de Castillo y Osterling, ${ }^{17}$ en la responsabilidad civil ante el incumplimiento:

Para concluir con el tema fundamental de las obligaciones de medios y de resultados frente a la responsabilidad civil [...] hemos querido exponer la teoría de René Demogue que dio nacimiento a esta materia y luego citar algunas posiciones esbozadas por la doctrina, pero fundamentalmente hemos deseado dejar en claro nuestra tesis adversa a distinguir las obligaciones en aquellas que pudieran ser de medios y otras que pudieran ser calificadas como de resultados (2000).

\section{Controversia}

La definición del contrato de secuestro contenida en nuestro Código Civil menciona el término controversia, que significa, a la luz de reconocida doctrina nacional y extranjera, "el debate judicial o extrajudicial entre los secuestrantes respecto de la cosa común, respecto de algún derecho individual sobre ella" (Arias-Schreiber 1995: 227). Por lo tanto, la controversia de dos o más secuestrantes implica un debate jurídico entre personas que pretenden un derecho individual sobre la misma cosa, un conflicto de intereses no resuelto. ${ }^{18}$

17 El soberbio ensayo del que se extrae la cita llegó a nuestras manos por gentil cortesía del doctor Mario Castillo Freyre.

18 Es importante resaltar que el Código no exige que la controversia haya ingresado ya al terreno del litigio (arbitral o judicial). En efecto, no debemos distinguir donde la ley no distingue; por tanto, debemos entender que bastará, para hablar de controversia, que existan dos o más personas vinculadas por una común diferencia sobre el derecho a una misma cosa, esté o no en terreno judicial. 


\section{Administración del bien secuestrado}

La administración del bien secuestrado es una norma de excepción. ${ }^{19}$ En efecto, tal situación quiebra el principio general del contrato de depósito, según el cual el depositario no debe usar la cosa. Si el secuestratario usa la cosa para beneficio propio, estamos ante la figura general del depósito irregular. Por el contrario, la norma menciona administrar y no usar, por lo que el secuestratario deberá realizar actos de administración en interés de los depositantes, hasta que concluya el secuestro convencional. Nuestro Código menciona: "cuando la naturaleza del bien lo exija", como el supuesto de hecho para que el secuestratario esté constreñido a administrar la cosa secuestrada, dando a entender que, verificado el supuesto, el secuestratario no podrá evadir dicha obligación. Veremos, a continuación, las situaciones que se pueden presentar en la práctica y sus consecuencias jurídicas.

En el secuestro convencional, el secuestratario no administra para sí; administra la cosa en representación y beneficio de los secuestrantes, los que otorgan al depositario un mandato con representación para que realice los actos de administración necesarios frente a terceros: usa la cosa en tanto la debe administrar en provecho ajeno - de los secuestrantes-. Entonces, podemos afirmar que dentro del secuestro convencional, en los casos que así lo requieran, los secuestrantes deberán extender un mandato con representación al depositario para que cumpla con la obligación legal de administrar el bien, en caso de que la administración haya nacido junto con el contrato de secuestro. Así, se consagra una necesaria mixtura de figuras contractuales: la categoría de los llamados contratos mixtos (Messineo 1979: 293).

En este mandato con representación importa que los contratantes, en el momento de celebrar el contrato, prevean las circunstancias que rodearán la ejecución del secuestro convencional y, por tanto, de la posible administración del bien. No cabe duda de que si el bien es productivo, los contratantes suscribirán el secuestro convencional imponiéndole al secuestratario la obligación de que la cosa siga produciendo, dentro de ciertos límites. Entonces, la administración del

19 Artículo 1859.- Cuando la naturaleza del bien lo exija, el depositario tiene la obligación de administrarlo. 
bien secuestrado, como hipótesis general, será aquella prevista por los contratantes en el momento de la celebración del contrato.

Debemos señalar que hay bienes que son susceptibles de administración y bienes que no lo son. ${ }^{20} \mathrm{Ha}$ de recordarse, asimismo, que pueden ser objeto del contrato de secuestro tanto bienes muebles como inmuebles; estos últimos sí están destinados a una actividad económica productiva (por ejemplo: un restaurante, un hotel, un fundo agrícola, etc.), y no cabe la menor duda de que si fueran secuestrados convencionalmente, deberán ser administrados a fin de que la actividad productiva no se detenga. La duda se presenta respecto de los bienes muebles, pues ellos deberán ser administrados en tanto representen una fuente de explotación económica o estén afectados a unidades de producción (por ejemplo: maquinaria pesada para la construcción), siempre que estén en vida útil. Esta complicada situación genera, en la práctica, grandes problemas para determinar cuáles bienes muebles serán o cuáles no serán objeto de administración.

En teoría, todos los bienes son susceptibles de ser administrados, pues todos tienen una función económica que cumplir, pero no sucede así en la práctica. A nuestro juicio, para que se dé la administración del bien secuestrado convencionalmente, este debe estar dentro de su vida útil, que la controversia surja durante la explotación económica del bien, de forma tal que paralizar su explotación importaría un potencial perjuicio económico para todos los secuestrantes, y que el secuestratario sea apto para ello, es decir, sea una persona experta en la administración del bien secuestrado.

La norma no señala tampoco quién decide acerca de si se debe o no se debe administrar la cosa secuestrada en los casos de administración sobreviniente a la celebración del contrato. En apariencia, esta es una facultad discrecional del secuestratario, de suerte tal que será él quien decida cuándo, cómo y dónde administrar la cosa secuestrada. Así parece sugerirlo la doctrina nacional: “La obligación a que se refiere este precepto está vinculada con la naturaleza de los bienes que el secuestratario tiene bajo custodia, ya que mientras algunos deberán ser adminis-

20 “La obligación a que se refiere el precepto está vinculada con la naturaleza de los bienes que el secuestratario tiene bajo custodia, ya que mientras algunos deberán ser administrados, otros no podrían serlo" (Arias-Schereiber 1995: 235). 
trados, otros no podrían serlo" y "Desde el momento en que el secuestratario (depositario) administra el bien o bienes entregados en secuestro, estará obligado a dar cuenta de esa función" (Arias-Schreiber 1995: 235-236). En nuestra opinión, ello resulta peligroso.

En efecto, no existirá riesgo alguno para los secuestrantes en aquellos secuestros convencionales en donde las partes han pactado que la administración de la cosa corresponde al secuestratario, otorgándole facultades expresas para ello en el momento de celebrar el contrato. Sin embargo, como hemos mencionado, la inseguridad jurídica se cierne sobre aquellos secuestros con administración sobreviniente, en donde el contrato no prevé facultades y demás atribuciones para el secuestratario, ni circunstancias de necesaria regulación que hagan viable la ansiada administración en beneficio de los secuestrantes. No dudamos de que esta situación será una inagotable fuente de conflictos entre los contratantes y contribuirá a desalentar la celebración de secuestros convencionales, no solo por desconocimiento de la figura contractual, sino por el alto costo transaccional que deberán afrontar los depositantes en el mercado frente a una laguna jurídica existente en la norma comentada -inseguridad jurídica-, que no disminuye el riesgo sobre la cosa para los secuestrantes. Esta no es, a nuestro juicio, la hipótesis del artículo 1859 del Código Civil. ${ }^{21}$ En esta hipótesis, el secuestratario deberá recabar autorización para administrar de los secuestrantes, quienes incluso están en derecho de negarla.

Toda obligación de administrar genera siempre la de rendir cuentas de la administración. En efecto, la obligación de rendir cuentas es ínsita a la de administrar y se genera a partir de la conclusión del secuestro convencional o del acto de administración, lo que ocurra primero. La norma no la menciona; tampoco lo hace respecto de la oportunidad, la forma y su contenido, temas propios de una rendición de cuentas convencional o voluntaria. Claro está que, en caso de que no sea efectuada de manera voluntaria, puede solicitársela por vía judicial.

A consecuencia de la temporalidad del contrato de secuestro y de que su finalidad es cautelar, el Código menciona que los contratos suscritos bajo la administración del depositario quedan sometidos a las

21 Artículo 1859.- Cuando la naturaleza del bien lo exija, el depositario tiene la obligación de administrarlo. 
resultas del secuestro, ${ }^{22}$ el que probablemente concluya antes del vencimiento de los contratos celebrados, más aún si recordamos la relativa indeterminabilidad del plazo de vencimiento del contrato.

Debemos recordar que el contrato de secuestro es principal. Siendo también, por definición, temporal, resulta lógico suponer que concluirá en algún momento y que se entregará la cosa a quien resulte vencedor de la controversia. Los contratos temporales con obligación de dar no transmiten la propiedad, sino un derecho real de inferior jerarquía: la posesión (arrendamiento y comodato). Lo mismo sucede en los servicios - depósito y secuestro-, en donde el servicio depende del despliegue de actividades de custodia y conservación sobre una cosa. La expresión "si, antes del vencimiento del plazo" se refiere, qué duda cabe, al plazo de los contratos celebrados por el secuestratario con terceros, en la lógica y única hipótesis de que los contratos - también temporales por naturaleza y no transmisivos de propiedad-, sujetos a plazos determinados normalmente, vencen en fecha fija y es en el ínterin cuando concluye el secuestro.

La finalidad de la norma es evitar que el vencedor de la controversia no pueda disponer libremente de la cosa secuestrada, contrasentido que debe evitarse, pues, reiteramos, la administración de la cosa es un mero accidente de excepción en la vida del contrato y no su finalidad principal: el fin principal es cautelar la cosa a través de la obligación de conservación y custodia.

Con relación al derecho de los terceros cuyos contratos vencieron de pleno derecho por la conclusión del secuestro, a ser indemnizados, la norma no menciona nada, lo que sí sucede en el subarrendamiento. ${ }^{23}$ A falta de regla especial, esta omisión debe ser resuelta por las reglas generales.

Por último, quien administra una cosa a favor y beneficio de un tercero, no solo debe rendir cuentas, sino también ha de percibir los frutos

22 Artículo 1860.- Cualquier contrato que celebre el depositario de conformidad con lo dispuesto en el artículo 1859, concluye de pleno derecho si, antes del vencimiento del plazo, se pusiere fin a la controversia.

23 Artículo 1694.- A la conclusión del arrendamiento se extinguen los subarrendamientos cuyos plazos no han vencido, dejándose a salvo el derecho del subarrendatario para exigir del arrendatario la indemnización que corresponda. 
y entregarlos cuando aquella sea restituida. En efecto, los frutos pertenecen a quien resulte vencedor de la controversia: aquel deberá exigir la rendición de cuentas pertinente, así como la restitución de la cosa y entrega de los frutos. El secuestratario no podrá, por ningún motivo, apropiarse de los frutos o rentas percibidos durante su administración, pues estaría enriqueciéndose indebidamente en perjuicio de un tercero. Tan solo podrá retener la cosa y sus frutos, bajo la forma del derecho de retención, en el caso de que no les sean pagados sus gastos de administración y custodia y la contraprestación pactada, si la hubiera. Una vez satisfecho el crédito, debe entregar la cosa con todos sus accesorios a quien resulte acreedor de la cosa controvertida.

En cuanto a la legislación comparada, pocos son los códigos civiles que regulan en forma expresa la administración de la cosa secuestrada. Los códigos de Chile (artículo 2255), Colombia (artículo 2279) y Uruguay (artículo 2290) tratan el tema con una redacción diferente de la del artículo 1859 de nuestro Código, que de manera expresa permite la administración, dependiendo de la naturaleza del bien. La redacción usada por dichos códigos es textualmente la misma: "El secuestratario de un inmueble tiene, relativamente a su administración, las facultades y deberes de mandatario y deberá dar cuenta de sus actos al adjudicatario". 24

24 Esta redacción presupone la administración del bien y le otorga facultades de mandatario al secuestratario, lo que no menciona nuestro Código Civil. 


\section{Bibliografía}

ALBALADEJO, Manuel (1994). Derecho civil. Tomo II. 9. ${ }^{a}$ edición. Barcelona: Bosch.

ARIAS-SCHREIBER PEZET, Max (1995). Exégesis del Código Civil peruano de 1984. Tomo III. Lima: Gaceta Jurídica.

CASTILLO FREYRE, Mario y Felipe OSTERLING PARODI (2000) “El tema fundamental de las obligaciones de medios y resultados frente a la responsabilidad civil". Derecho 53. Lima: Facultad de Derecho de la Pontificia Universidad Católica del Perú.

COLIN, Ambrosio y Henri CAPITANT (1949). Curso elemental de derecho civil. Tomo IV. 2. a edición. Madrid: Reus.

DÍEZ-PICAZO, Luis y Antonio GULLÓN (1990). Sistema de derecho civil. Tomo II. 6. ${ }^{\text {a }}$ edición. Madrid: Tecnos.

FLORES POLO, Pedro (1984). Diccionario de términos jurídicos. Tomos I y II. 1. a edición reimpresa. Lima: Editores Importadores.

MAZEAUD, Henri y Jean LEÓN (1979). Lecciones de derecho civil. Tomo III. Buenos Aires: Ediciones Jurídicas Europa América.

MESSINEO, Francesco (1979). Manual de derecho civil y comercial. Tomo V. Buenos Aires: Ediciones Jurídicas Europa América.

PETIT, Eugene (1980). Tratado elemental de derecho romano. Buenos Aires: Albatros.

REAL ACADEMIA ESPAÑOLA. Diccionario de la lengua española. $<\mathrm{http}: / /$ www.rae.es>. [Consulta: 10 de diciembre del 2008.] 